
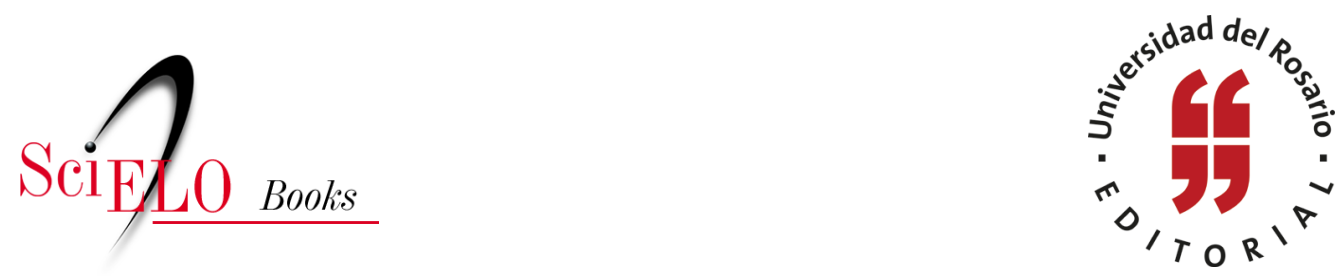

\title{
Los escaparates del progresso Brasil en las exposiciones internacionales del siglo XIX
}

\author{
Margarida de Souza Neves
}

\section{SciELO Books / SciELO Livros / SciELO Libros}

SOUZA NEVES, M. Los escaparates del progresso: Brasil en las exposiciones internacionales del siglo XIX. In: SCHUSTER, S., ed. La nación expuesta. Cultura visual y procesos de formación de la nación en América Latina [online]. Bogotá: Editorial Universidad del Rosario, 2014, pp. 83-99. Textos de ciencias humanas collection. ISBN: 978-958-738-524-3. https://doi.org/10.7476/9789587385243.0006.

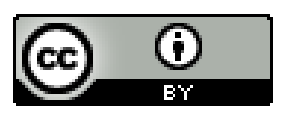

All the contents of this work, except where otherwise noted, is licensed under a Creative Commons Attribution 4.0 International license.

Todo o conteúdo deste trabalho, exceto quando houver ressalva, é publicado sob a licença Creative Commons Atribição 4.0.

Todo el contenido de esta obra, excepto donde se indique lo contrario, está bajo licencia de la licencia Creative Commons Reconocimento 4.0. 


\title{
Los escaparates del progreso: Brasil en las exposiciones internacionales del siglo XIX
}

\author{
Margarida de Souza Neves \\ Pontifícia Universidade Católica do Rio de Janeiro
}

El título de este ensayo es también su hipótesis central: las exposiciones internacionales consideradas escaparates — vitrines, en portugués de Brasil (Neves 1986, 1-70); Schaufenster, en alemán, y shopwindows, en inglés- donde se expone y se impone la ideología del progreso, que asumió una función análoga a la de una religión laica y que presidió la historia cultural de Occidente desde la mitad del siglo XIX hasta que las guerras mundiales pusieron en entretela su supuesto fundamental, según el cual las naciones civilizadas y progresistas habían sustituido la barbarie de la guerra por la emulación del ingenio y del arte, encontraban en las muestras internacionales su mejor expresión y su traducción escenificada.

Algunas imágenes pueden empezar a dar contenido a esa hipótesis y a establecer la relación entre las exposiciones internacionales y la construcción de la ideología del progreso. Una de ellas aparece en la página de apertura del libro Recollections of the Great Exhibition $(1851,1)$, distribuido como recordatorio de la primera de las muestras internacionales, realizada el 1851 en el mítico Palacio de Cristal, dibujado por John Paxton para abrigar el evento. En el centro de la imagen figura una hornacina en hierro forjado hecha por los artesanos de Coalbrookdale, bajo la cual se puede ver a Shakespeare. Alrededor de la hornacina está una multitud formada por gente, supuestamente, de todas las partes del mundo.

La asociación de esa imagen con el universo religioso, con el lugar que Europa pretende ocupar en la historia de la cultura y de la civilización y con el carácter pedagógico de la Exposición Universal no son difíciles de inferir: la hornacina encimada 
por una figura alada y también la figura de Shakespeare remiten de inmediato a una sintaxis visual religiosa, sin duda subrayada por la liturgia, los ritos y las procesiones cívicas de la exposición misma. Y si es verdad que los chinos, los bérberos, los turcos y los indianos que figuran en traje de fiesta están allí para atestar la universalidad de la muestra, así como la presencia de civiles y de militares; de hombres y de mujeres; de niños y de personas mayores; de aristócratas y de gente más bien sencilla señala la presencia de un público diversificado, el tope de la jerarquía parece incontestablemente ocupado por el discreto e impecable caballero de sombrero de copa alta y bastón, dibujado a imagen y semejanza del príncipe Albert, idealizador de la muestra. Y es él, el europeo (inglés en el caso) civilizado y culto, quien enseña a los demás el sentido de la lección indeleble de todas las exposiciones internacionales. Es una lección de historia, comprendida como evolución que a todos los pueblos sitúa en una misma y rectilínea vía: la que propone una parusía inmanente representada por el progreso, sinónimo de civilización, que reduce diferencias culturales a desigualdades y en la cual el paradigma es definido por el modelo, las prácticas y los valores de Europa occidental (figura 1).

Esa misma lección es la que aprenden las dos niñas en el libro que tienen entre manos, con toda probabilidad The Children's Prize Gift Book of the Great Exhibition of 1851 (1851, 1 y 2), distribuido por los organizadores a los pequeños (figura 2).

Las exposiciones, sus carteles, sus publicaciones y los que sobre ellas escribieron en su época no cesan de repetir esa lección: "La misión de nuestra época es la civilización del mundo entero" (Vervynnck y Dubois 1867, 42). O, tal como lo quiso François Guizot: "La civilización es una luz, y la luz se hace siempre más intensa. La civilización es una, y consiste en un proceso de desarrollo que tiende siempre hacia un mismo fin: el perfeccionamiento de la humanidad" (citado en Nicéforo 1961, 14).

El conocido cuadro de Georges Garen, pintado por ocasión de la inauguración de la Torre Eiffel en la Exposición Internacional de 1889, traduce en imagen las palabras de Guizot. En este, la torre proyectada por Gustave Eiffel, en aquel entonces la más alta construcción hecha por la mano del hombre, aparece como un faro capaz de romper la oscuridad de la noche y presentarse como un monumento a la luz, símbolo mayor del progreso y de la civilización (figura 3). 


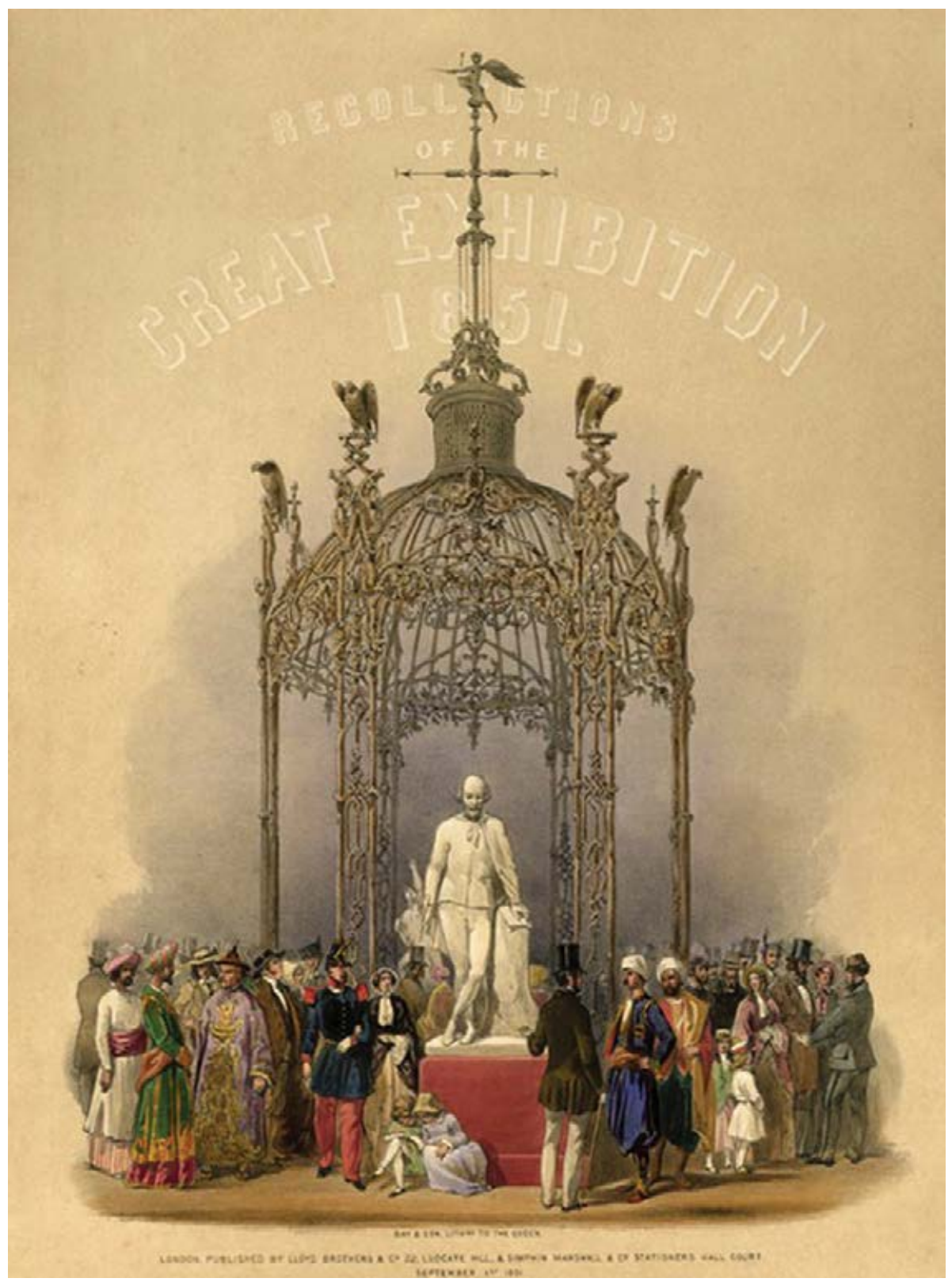

Figura 1. Página de apertura del libro recordatorio de la Exposición de Londres, 1851

Fuente: Kenneth Spencer Research Library, University of Kansas, Lawrence. 


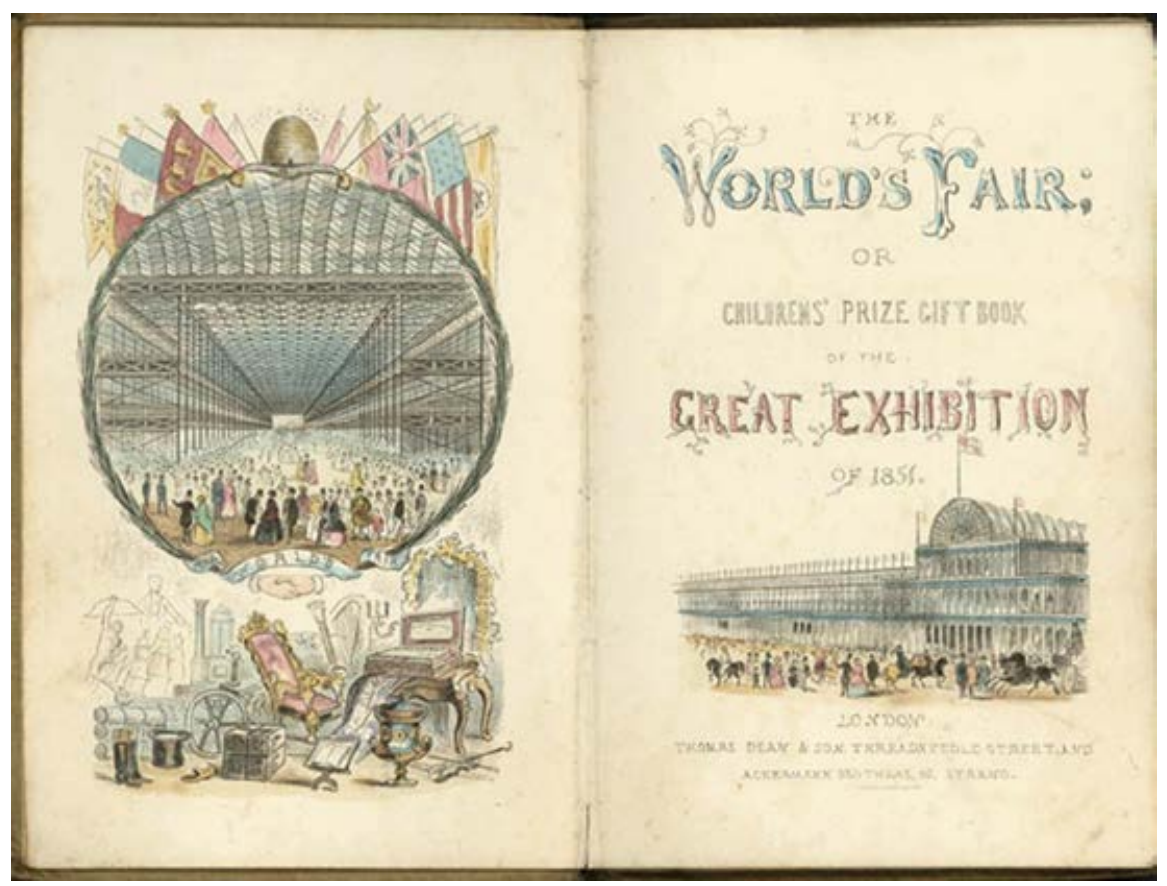

Figura 2. Portada del libro The World's Fair Children's Prize Gift Book of the Great Exhibition of 1851 Fuente: Kenneth Spencer Research Library, University of Kansas, Lawrence.

No sin razón el parangón con el universo religioso se repite en las formulaciones hechas por los estudiosos de la exposiciones internacionales: para Walter Benjamin, ellas son "Lugares de peregrinación a la mercancía-fetiche" $(1982,64)$ y, más recientemente, Umberto Eco las califica de "Verdaderas catedrales laicas" (1984, 292). La visualidad que de ellas nos llega lo confirma (figura 4).

¿Qué lugar ocupaba el Imperio de Brasil en las exposiciones internacionales del siglo XIX? Brasil no tuvo una representación oficial cuando el Palacio de Cristal se inauguró en 1851 y todas las miradas del así llamado mundo civilizado se volvieron hacia la Inglaterra victoriana. Tampoco la tuvo en París, en 1855, durante la segunda Exposición Internacional.

En 1861, sin embargo, fue organizada en Río de Janeiro una Exposición Nacional. De ella salen los artefactos destinados a representar al país en su estreno en estas muestras, por ocasión de la Exposición Internacional de 1862, en Londres. De esa primera exposición brasileña nos ha quedado una rica documentación iconográfica (Neves 2001, 173-206). 


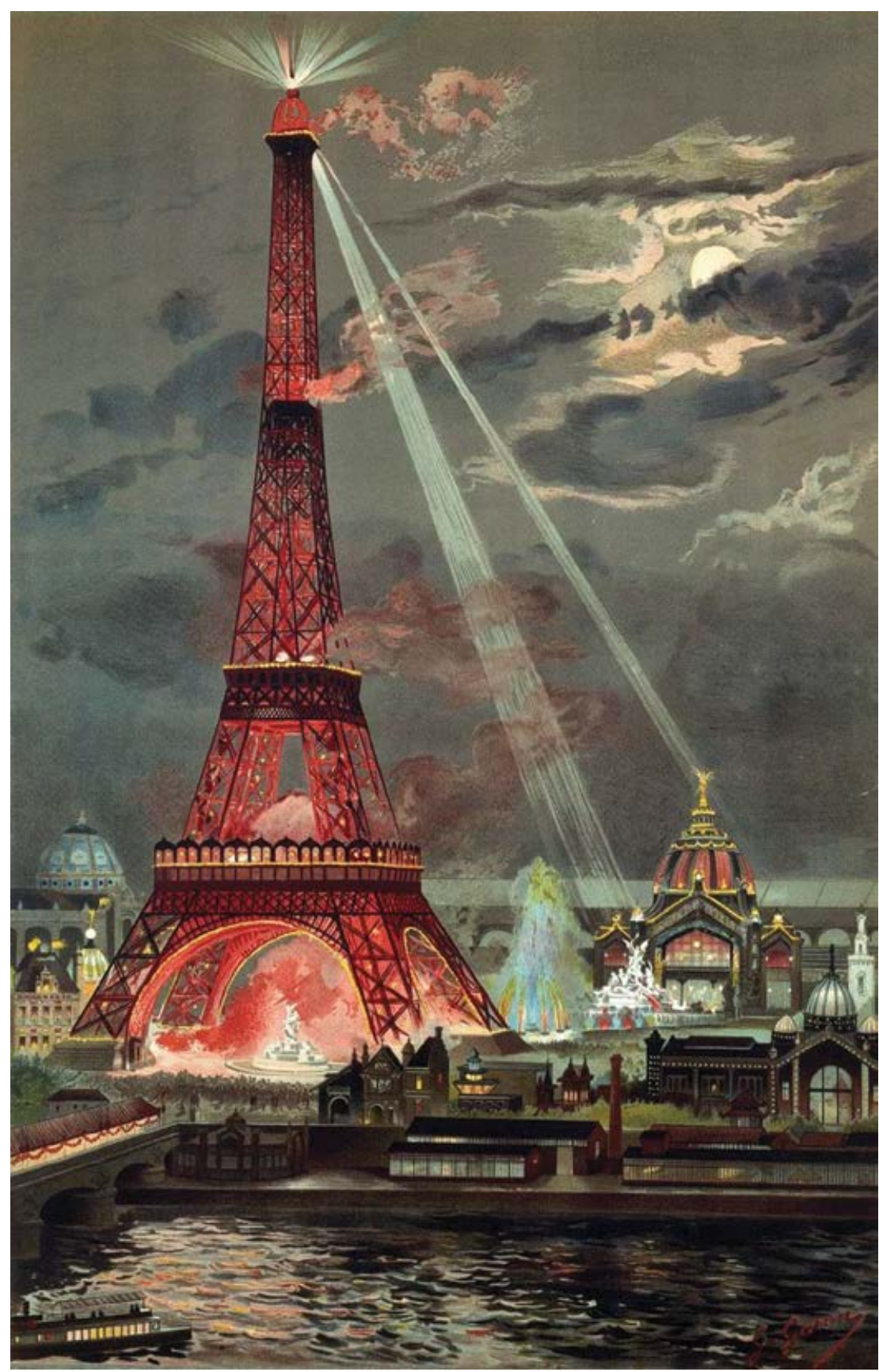

Figura 3. Georges Garen, 1989, Embrasement de la Tour Eiffelpendant l'Exposition Universelle de 1889, (grabado, $65 \times 45 \mathrm{~cm}$, Musée d'Orsay, París) 


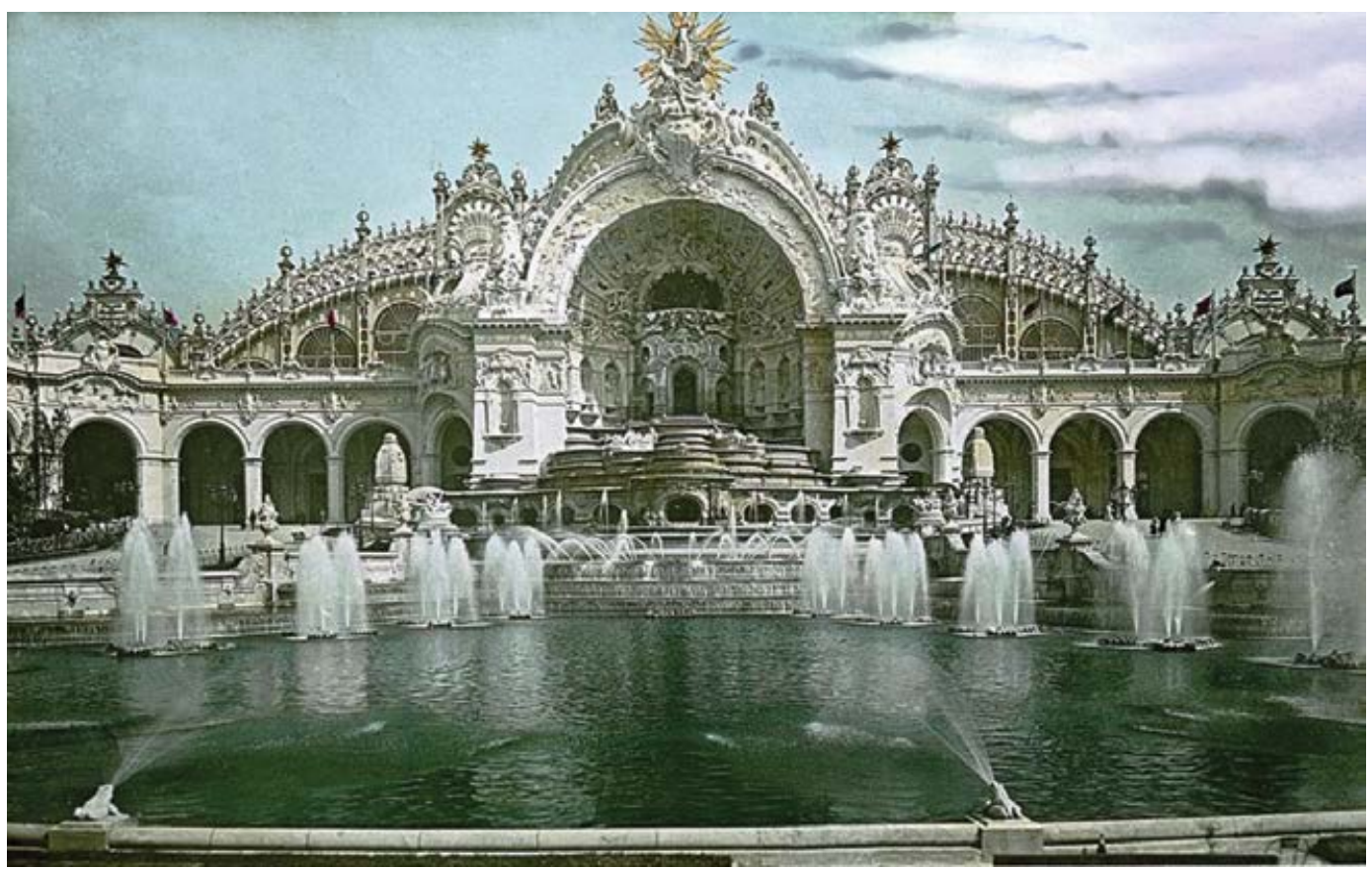

Figura 4. Paris Exposition: Palace of Electricity and Chateau of Water. Fotografia, 1900

Fuente: Brooklyn Museum Archives, New York City.

La Exposición Nacional tuvo lugar en una opaca, pesada y antigua construcción donde se ubicaba la Escuela Central de formación de ingenieros militares, y su visión no podría ofrecer un contrapunto más elocuente a la arquitectura hecha de transparencia y funcionalidad del Palacio de Cristal. Un grabado oficial hecho para eternizar el viejo edificio travestido en palacio de la muestra nacional nos lo enseña con la inscripción que atesta la nueva función asumida y el cercado de coches de caballos; de caballeros de frac y damas de capa y tocado, muy parecidos a aquellos que aparecen en la iconografía de la primera exposición inglesa, aunque el calor tropical no recomendara esos trajes. Un detalle, además de las palmeras y las banderas enarboladas, ubica al observador atento del grabado: una mujer negra en trajes de africana de la etnia mina con su niño. Sus pies descalzos denuncian tratarse de esclavos. Es una de tantas esclavas que venden golosinas por las calles para el lucro de sus propietarios (figura 5). 


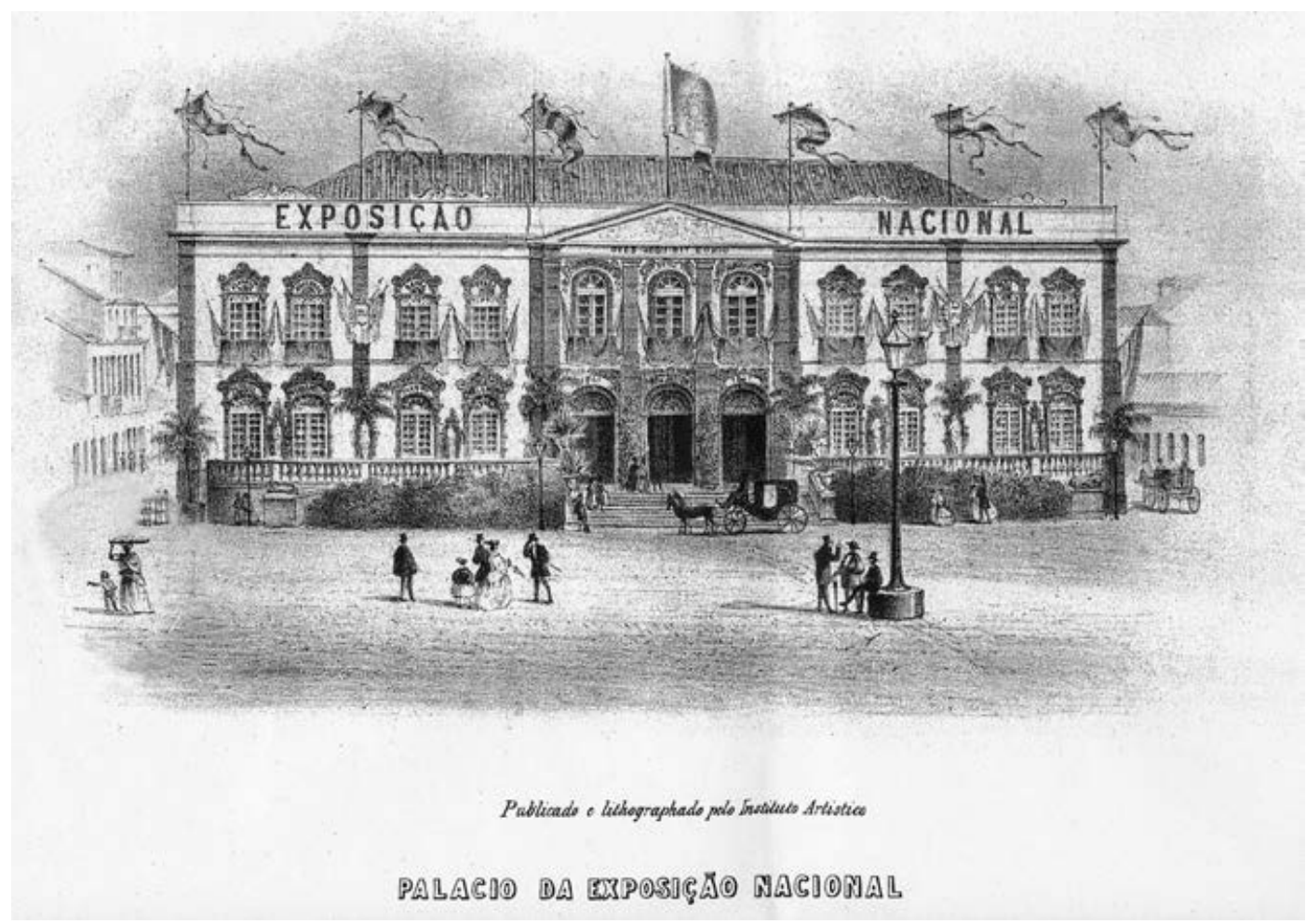

Figura 5. Palacio de la primera Exposición Nacional del Imperio de Brasil, 1861

Fuente: Trigueros (1977).

De ese edificio salieron los artefactos premiados en la muestra nacional para representar al Imperio de Brasil en la Exposición Internacional montada en South Kensington, en 1862. Entre la multitud que visitó esta Exposición Universal figuraba un testigo de excepción que dejó sus impresiones registradas: Karl Marx, que señaló en el capítulo 13 de El capital $(1980,432)$ su perplejidad ante una máquina capaz de transformar, en tan solo un minuto, una pila de papel cartón en trescientas cajas perfectamente cortadas, plegadas y rematadas, maravilla de la técnica que a la vez condena al desempleo a los trabajadores que antes las hacían manualmente.

¿Qué imagen del Imperio de Brasil es posible identificar en el conjunto de objetos y productos enviados a la muestra de 1862 donde, una vez más, se repasaron las lecciones del catecismo de una dada modernidad, compendiado en todas las 
exposiciones, en el cual se articulaban el progreso como ley universal, la apología del trabajo como fundamento de una nueva ética y la prometida paz universal como resultado de un sistema de cuya bondad intrínseca, armonía y racionalidad los idealizadores, los realizadores y buena parte de los visitantes parecían absolutamente convencidos?

Esa imagen puede ser encontrada en los grabados que componían el Álbum recordatorio de la Exposición Nacional Brasileña del 1861 (Trigueros 1977) que, además de reproducir en grabados lo expuesto en Río de Janeiro, traía un prólogo extremadamente interesante y señalaba los premios distribuidos, o sea, permitía identificar aquello que fue seleccionado para ser el retrato de Brasil presentado en Londres, en 1862.

La portada misma del Álbum dice ya mucho: en oro sobre negro figuran en ella las armas del Imperio con su rica simbología heráldica, en la que se destacan los ramos de café con sus frutos a un lado y de tabaco florecido al otro; la esfera armilar y la cruz de la Orden de Cristo heredadas de la tradición portuguesa; la cinta con las 18 estrellas que representaban las 18 provincias de entonces; la corona imperial y la gran cruz de la Orden de la Cruz del Sur. Sello del protagonismo del Estado imperial en la realización de la Exposición, las armas se presentan bajo un dosel idéntico a aquel que, de hecho, existía sobre el trono del emperador, sin prescindir de la tautología de una segunda corona imperial. Bajo las armas en oro, un pórtico que destaca la riqueza de la flora brasileña, donde plataneros, yucas, palmeras de todo tipo y helechos, se mezclan con flores más o menos europeas que, a su vez, se entrelazan con columnas corintias para señalar la síntesis entre la tradición clásica y la fuerza de la naturaleza de los trópicos lograda por el Imperio (figura 6).

Justamente la riqueza natural inconmensurable es el primer rasgo del retrato de Brasil enviado a Londres: maderas y piedras preciosas, pieles de animales de la selva y, cómo no, productos agrícolas entre los cuales se destacaban distintos tipos de café, ya para entonces un producto en franca expansión en el sudeste de Brasil y en el elenco de exportaciones del país. En por lo menos uno de los casos, la carnaúba, la planta fue presentada en la muestra de Río tanto in natura como manufacturada. Algunos de los productos hechos de la carnaúba fueron enviados a Londres y, con ellos, fue también el grabado de la palmera que los visitantes de la Exposición Nacional vieron al vivo y en colores (figura 7). 


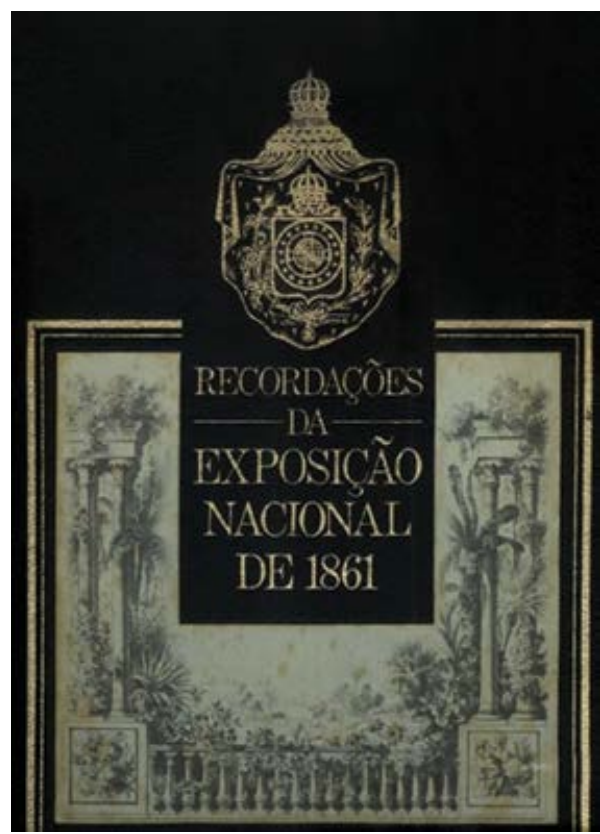

Figura 6. Portada del libro Recordações da Exposição Nacional de 1861 Fuente: Trigueros (1977).

Además de ese primer rasgo, que pretendía evidenciar la potencialidad de Brasil por la vía del subrayado en la fertilidad de su tierra, en las riquezas de su subsuelo y en la variedad de su fauna y flora, un segundo elemento caracterizaba la representación enviada por el Imperio de Brasil a Londres: el culto a la máquina como ícono de los nuevos tiempos, como para señalar que el Imperio de Brasil ingresaba a pasos largos en el sendero del progreso y sabía añadir a sus riquezas naturales las bases del desarrollo industrial.

Las circunstancias materiales y, sobre todo, el elevado coste que eso supondría hicieron imposible el traslado físico de esas máquinas fabricadas en Brasil a Londres, pero la muestra brasileña las incorporó en imágenes. Algunas de ellas son de una simpleza casi enternecedora. Otras son más complejas, salidas de las fábricas establecidas por el barón de Mauá. De todos modos, Marx no dejó constancia de haberse dejado impresionar por las imágenes de las máquinas brasileñas (figura 8). 


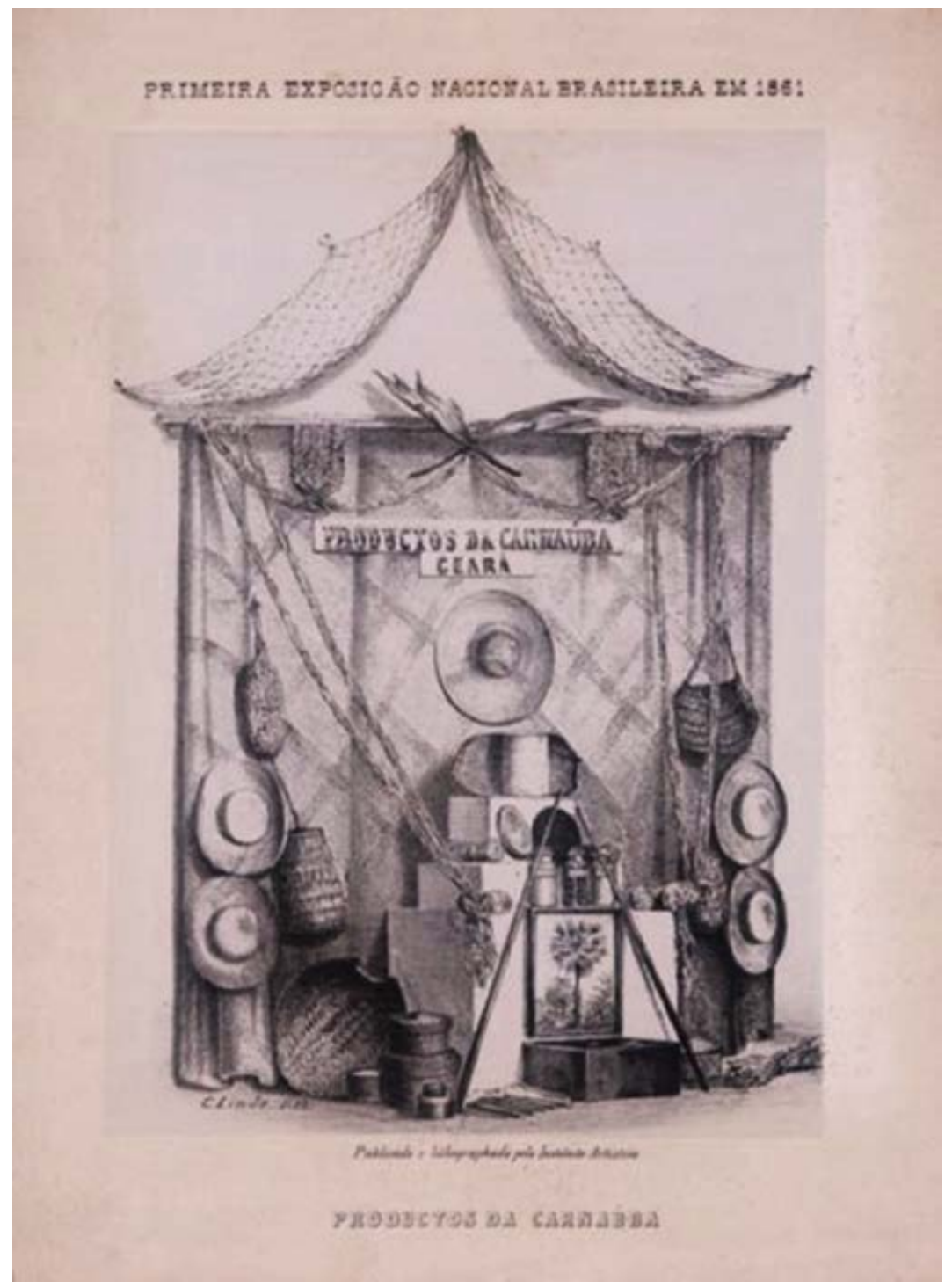

Figura 7. Productos de la carnaúba y representación de esa palmera

Fuente: Trigueros (1977). 


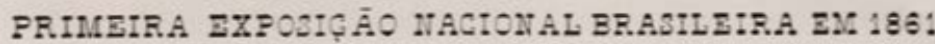

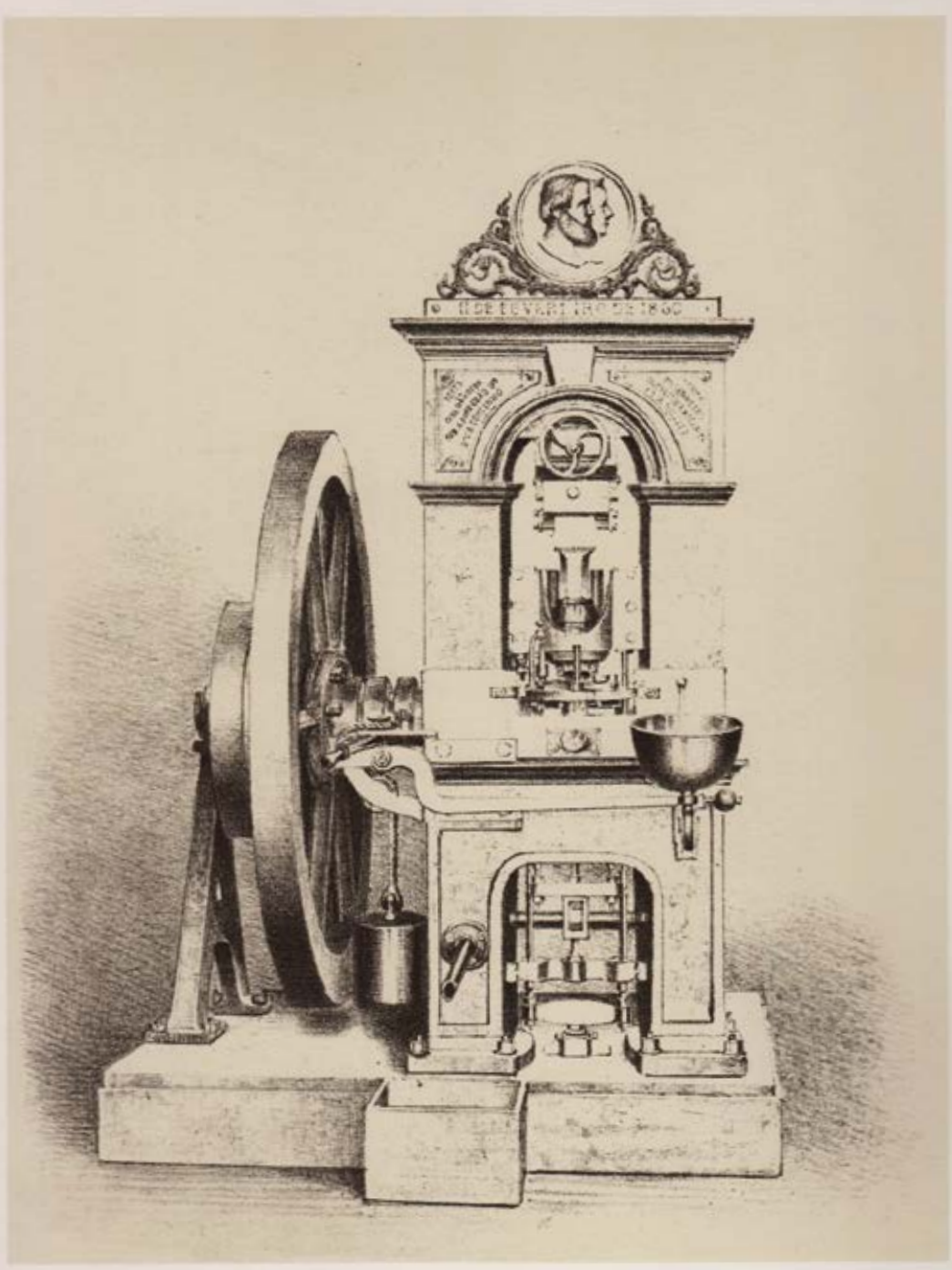

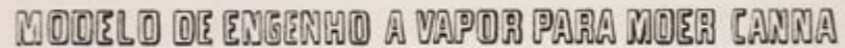

Feito pelo Sñ José Maria da Conceiçào Junior

Figura 8. Máquina para moler caña de azúcar con la efigie del emperador Fuente: Trigueros (1977). 
Un tercer rasgo reproducía, en la representación del país que el Imperio envió a Londres en 1862, el lugar destinado por la visión de mundo propia de los organizadores de aquella muestra internacional: la de un país lejano y exótico.

El exotismo aparece en algunos de los objetos extraños enviados, por ejemplo, en una imagen de santa Úrsula hecha con caracoles y conchas del mar o en ese ramo de flores en el que la materia prima son plumas de aves de la provincia de Bahía. Pero nada se compara al cuadro titulado Indígenas, obra seguramente de un artista que jamás en su vida había visto a un indígena brasileño, sino en las pinturas románticas que hicieron de él un símbolo de la brasilidad y que merece una mirada más cercana (figura 9).

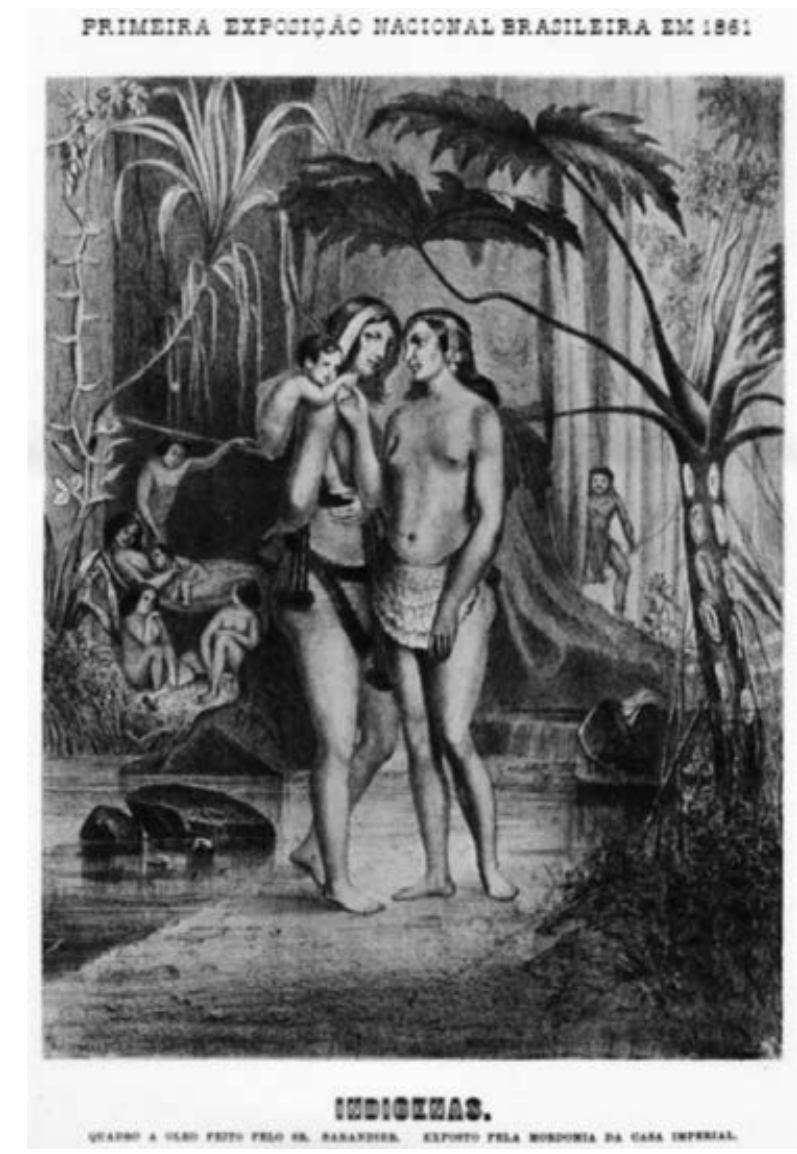

Figura 9. Indígenas, cuadro enviado por Brasil a la Exposición de 1862 Fuente: Trigueros (1977). 
En primer lugar, hay que destacar la naturaleza, que figura como un recuadro que destaca las figuras centrales. Es una naturaleza plácida y más lejana de la selva tropical que sus simulacros trasplantados a los jardines botánicos de Europa.

Luego, las tres figuras centrales, dos mujeres y un niñito presumiblemente indígenas. Sus cuerpos, sus atuendos, su actitud corporal, sus rasgos y sus peinados nada tenían que ver con los indígenas brasileños reales. La mujer que lleva el niño a la espalda más parece una dama salida de un cuadro italiano y la otra es un híbrido de adolescente occidental y noble inca. El niñito, con su mechón de pelo rizado en la frente, es el colmo del etnocentrismo europeo incorporado por el imaginario brasileño.

Otros indígenas componen también el cuadro. A la derecha, se encuentra un grupo formado por algunas mujeres, un hombre y un niño aparentemente macrocéfalo, no propiamente un éxito pictórico desde el punto de vista estético, aunque tenga el mérito de presentar la mujer y el niño en una hamaca, artículo que, por cierto, figuraba en distintas versiones en espacio destinado a Brasil en la Exposición. El colofón, sin embargo, es la figura del guerrero indígena que sale de detrás de los árboles a la izquierda del cuadro teniendo en sus manos el arco y las flechas y que el artista dibujó con largos y tupidos bigotes napoleónicos (figura 10).

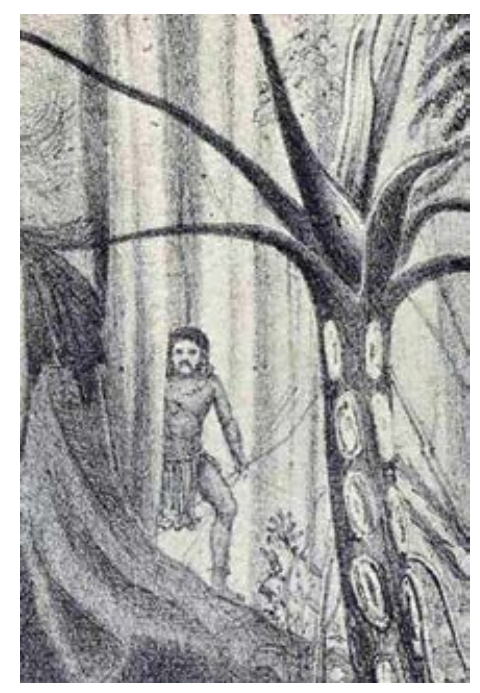

Figura 10. Detalle del cuadro Indigenas

Fuente: Trigueros (1977). 
Además del exotismo, sintetizado en la insólita escena indígena, otro rasgo caracteriza la nación brasileña expuesta en la Exposición Internacional de 1867: la constante presencia de las marcas de distinción del Imperio y del emperador, en las armas imperiales aplicadas en los objetos expuestos, en la efigie del emperador D. Pedro II presente en artefactos, en los dragones heráldicos de la casa real de Braganza esculpidos en el respaldo de un sillón, en el monograma del monarca bordado en hilo de oro sobre terciopelo negro, en el adorno que enlazaba las banderas que representaban en Londres al Imperio y sus provincias.

La nación brasileña expuesta en la Exposición Internacional de Londres en 1862 podría estar plasmada en la alegoría del imperio de Brasil hecha por Chaves Pinheiro diez años después de aquella muestra (figura 11): una nación joven, un Imperio que intentaba verse a sí mismo y hacerse ver como una síntesis de las tradiciones clásicas europeas y el nuevo mundo, a la vez guerrero indígena y soldado romano, con la mirada firme puesta en el futuro, seguro de sus riquezas naturales y de su potencialidad. Un Imperio exótico en el trópico, que creía tener en las insignias imperiales (el cetro, el manto y el escudo) el sello de su identidad. Así se presentó Brasil en la Exposición de 1862.

Fuera de la imagen del Imperio de Brasil llevada a la Exposición Internacional de Londres, como también estuvieron fuera del edificio donde se realizó la Exposición Nacional que la precedió, quedaban los esclavos que, lejos de las alegorías triunfalistas, sostenían sobre sus espaldas la frágil riqueza de aquel Imperio (figura 12). 


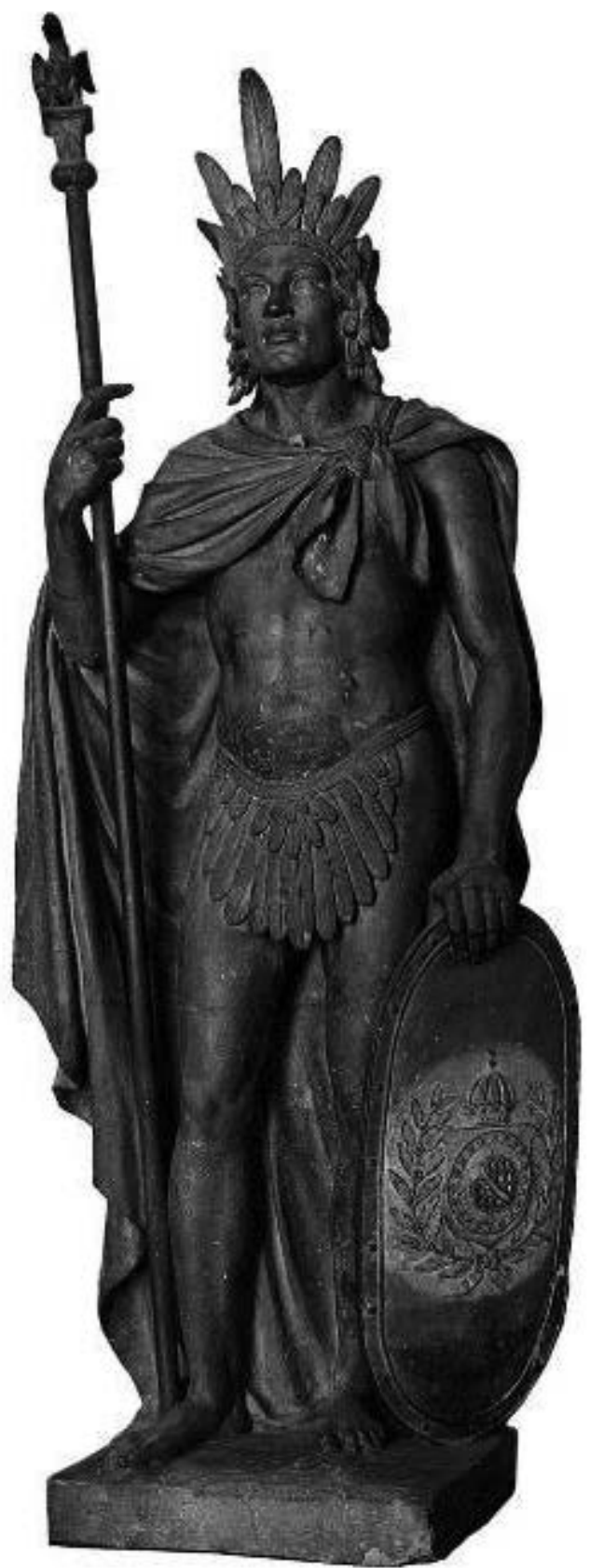

Figura 11. Francisco Chaves Pinheiro, 1871, Alegoria do Império Brasileiro (terracota, $192 \times 75 \times 31 \mathrm{~cm}$, Museu Nacional de Belas Artes, Rio de Janeiro) 


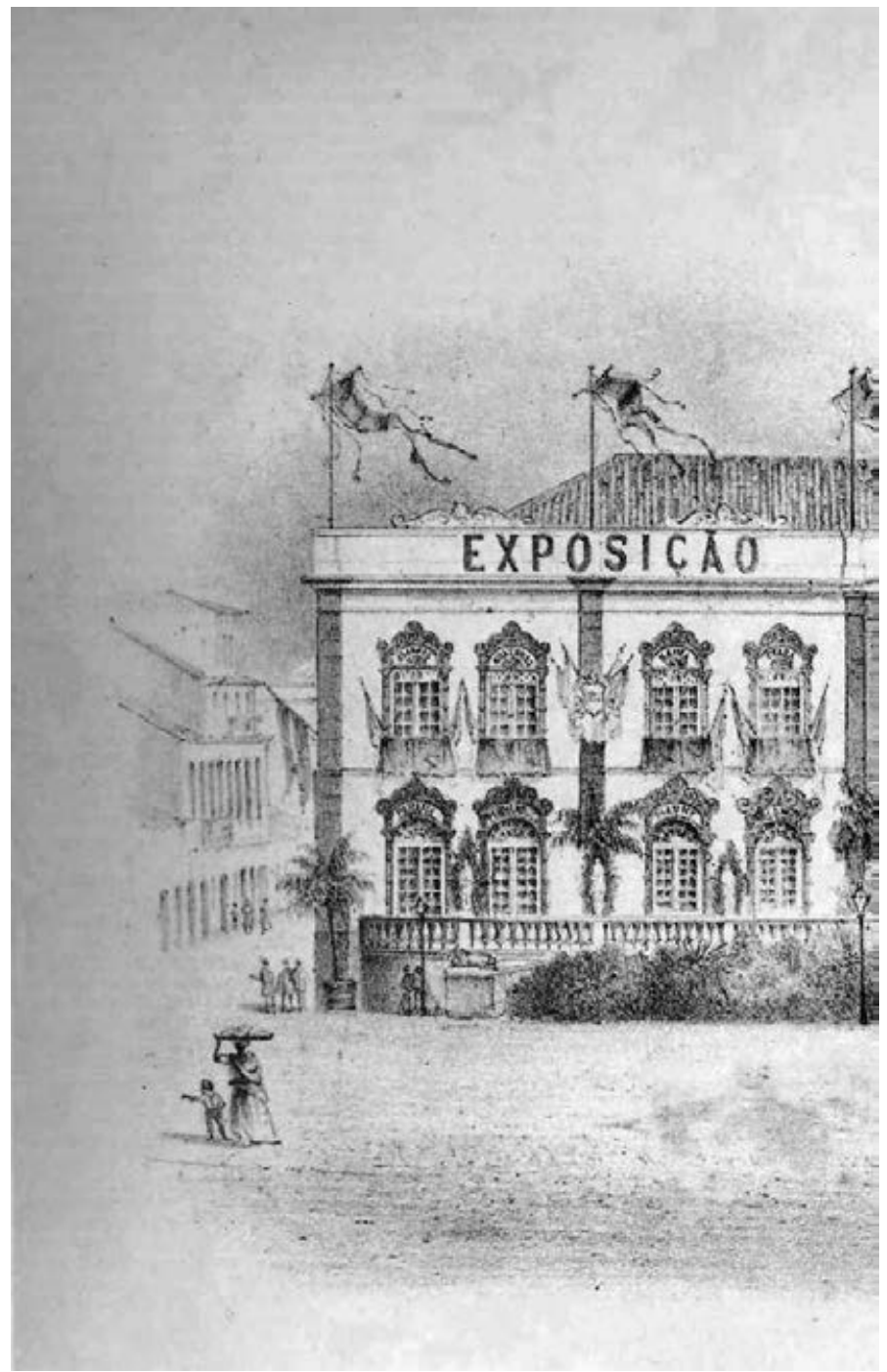

Figura 12. Palacio de la primera Exposición Nacional (detalle)

Fuente: Trigueros (1977).

\section{Bibliografía}

Benjamin, Walter. 1982 [1939]. “Paris, capitale du XIX ${ }^{\text {ème }}$ siècle”. En Das PassagenWerk, 60-77. Vol. 1. Frankfurt/M.: Suhrkamp.

Eco, Umberto. 1984. "O cogito interruptus". En Viagem na irrealidade cotidiana, 289-308. Rio de Janeiro: Nova Fronteira.

Marx, Karl. 1980. O capital. Vol. 1. Rio de Janeiro: Civilização Brasileira. 
Neves, Margarida de Souza. 1986. As vitrines do progresso. Rio de Janeiro: PUC-Rio. Neves, Margarida de Souza. 2001. “A 'Machina' e o indígena: o Império do Brasil e a Exposição Internacional de 1862”. En Ciência, civilização e império nos trópicos, editado por Alda Heizer y Antonio Augusto Passos Videira, 173-206. Rio de Janeiro: Access.

Nicéforo, Alfredo. 1961. El mito de la civilización: el mito del progreso. México: UNAM.

Recollections of the Great Exhibition. 1851. London: Lloyd Brothers.

The Children's Prize Gift Book of the Great Exhibition. 1851. London: Thomas Dean and Son-Ackermann \& Co.

Trigueros, Luís Forjas, editor. 1977 [1862]. Recordações da Exposição Nacional de 1861. Rio de Janeiro: Confraria dos Amigos do Livro (edición facsimilar).

Vervynnck, D. y E. Dubois. 1867. Histoire des expositions industrielles. Paris: E. Vert. 